\title{
High risk scoring for prediction of pregnancy outcome: a prospective study
}

\author{
Sapna Jain ${ }^{1}$, Sweta Anand ${ }^{2}$, Rupa Aherwar ${ }^{1}$ \\ ${ }^{1}$ Department of Obstetrics \& Gynecology, Chirayu Medical College, Bhopal, M.P., India \\ ${ }^{2}$ Department of Pediatrics, Chirayu Medical College, Bhopal, M.P., India
}

Received: 26 May 2014

Accepted: 10 June 2014

\section{*Correspondence:}

Dr. Sapna Jain,

E-mail: sapna.bajaj48@yahoo.com

(C) 2014 Jain S et al. This is an open-access article distributed under the terms of the Creative Commons Attribution Non-Commercial License, which permits unrestricted non-commercial use, distribution, and reproduction in any medium, provided the original work is properly cited.

\begin{abstract}
Background: Objectives of current study were to detect high risk factors in pregnancy and to develop a simple scoring system to identify and categorize high risk pregnancies and to predict neonatal outcome by prospective multifactorial analysis of high risk factors.

Methods: In this prospective study, antepartum, intrapartum and neonatal parameters were integrated into the clinical records and the relationship of risk score to outcome was evaluated for 415 randomly selected pregnant patients over a period of 1 year. Risk scoring was applied on selected mothers more than 28 weeks of gestation who presented in labour.

Results: Out of 415 women, 96 (59\%) were High Risk, 191 (46\%) were Low risk and 128 (31\%) were No risk. In High risk group there were 59 perinatal deaths and perinatal mortality rate was very high (614 per 1000 live births).

Conclusions: The risk scoring system can thus be used not only as a test for predicting perinatal mortality but also as a simple and cost effective screening tool for identifying pregnancies at higher risk of perinatal mortality and morbidity so that these are subjected to the special 'high risk' care they need.
\end{abstract}

Keywords: High risk pregnancies, Perinatal mortality, Scoring system

\section{INTRODUCTION}

A high-risk pregnancy (HRP) is one in which the maternal environment or past reproductive performance presents a significant risk to fetal well-being, such as premature birth ,small for date infant, full term with low reservoir or still births and early neonatal death. Identification of patients at risk for these complicated pregnancies with poor outcome is fundamental to antenatal care. Detection of HRP by developing a risk scoring system prioritizes the action for needy individuals especially in developing countries with scanty resources. It is essential that extra care be provided at least to those who deserve it most.

A high risk pregnancy may be identified by using a scoring system such as the system developed by Hobel et al. ${ }^{1}$ Risk scoring system may be defined as a formalized method of recognizing, documenting and cumulating antepartum, intrapartum and neonatal risk factors in order to predict complications for the fetus and new born.

The present study was aimed at developing a risk scoring system which is simple, effective and reliable in detecting 'at risk' cases and involves easily available information like history, clinical findings etc. it does not rely on sophisticated investigations which may be too expensive.

\section{METHODS}

It was a prospective study conducted at tertiary care center of central India over a period of 1 year, antepartum intrapartum and neonatal parameters were integrated into the clinical records and the relationship of risk score to 
outcome was evaluated for 415 randomly selected pregnant patients. Risk scoring was applied on selected mothers more than 28 weeks of gestation who presented in labour. Pregnant women were interviewed thoroughly and systematic clinical examination was carried out in order to determine the risks factors. All the mothers were subsequently followed up for the next 8 days postdelivery and the information regarding maternal complications and perinatal morbidity and mortality was gathered. Neonates under study included both those delivered at the hospital and also those referred to the neonatal unit for special care. Screening methods made use of arbitrarily selected risk factors derived from prior studies. A relative risk weight (score 0, 1, 2, 3, 4) was assigned to each variable according to the degree of insult with respect to anticipated perinatal outcome.

Values of all the high risk factors were summed up and a total score determined whether the pregnancy was "No risk" "low risk" or "high risk", accordingly and were categorized as:

No risk with the score of $0-3$,

Low risk with the score of 4-9,

High risk with the score of 10 or $>10$.

\section{Analysis}

Data were compiled and analyzed using the MS excel and Epi Info software (version 2002). Statistical tests used were chi-square and Student's $t$-test, and the $\mathrm{P}$ value of $<0.05$ was considered significant

\section{Variables of the scoring system and format}

In the risk scoring system used by us there are three predictive scales i.e. antenatal, intrapartum, and neonatal factors with 24 variables. There were 11 antenatal factors, 6 intrapartum factors and 7 neonatal factors. Mothers were interviewed for antenatal factors such as sociodemographic status, past reproductive performance, medical factors like tuberculosis, heart disease, and diabetes and other endocrine disorders, anemia. Anthropometric measurements like height and weight were recorded; factors like pregnancy induced hypertension, ante-partum hemorrhage, multiple gestation, premature rupture of membrane were detected. The intrapartum scale focused on problems of abnormal progress of labour, meconium stained liquor, fetal heart rate deceleration, presentation, induced labour and mode of delivery. Details about neonatal factors included were birth weight, gestational age, APGAR score, hypothermia, congenital anomalies and some of the important problems like birth asphyxia and respiratory distress. Each variable was allotted a minimal value or score of $0,1,2,3,4$ according to its negative effect on the fetus; with 0 score for no risk and 4 for maximum risk. Score for all high risk were added up and antepartum and intrapartum score was compared with neonatal score and perinatal outcome was predicted (in terms of perinatal deaths).

\section{Ethical clearance}

Informed verbal consent was obtained from all the study subjects. The procedures followed were in accordance with the ethical standards of the committee of our hospital.

\section{RESULTS}

High risk pregnancy is multifactorial in most of the cases and so all high risk patients had $>1$ directly or indirectly contributing high risk factor for mortality in most of the cases. We have not determined and emphasized on the perinatal mortality with the zero score in all the variables individually as these patients had other high risk factors contributing to the perinatal mortality.

In the present study majority of the mothers were in the age group of $19-34$ years $(97.4 \%)$ with a negative risk score, while remaining $2.6 \%$ were in the age group of $<18$ or $>35$ years with a perinatal death rate of $18.2 \%$. $18 \%$ of mothers were para three or more with the perinatal mortality of $33.3 \%$. Mothers with height $<145$ centimeters and weight $<40 \mathrm{~kg}$ are associated with similar higher mortality rates i.e. $15.3 \%$ and $18.2 \%$ respectively. Perinatal mortality is highest $(38.4 \%$ and $33 \%$ ), when mother is uneducated and her household monthly income is less than Rs. 500 respectively, as the chances of anemia, poor maternal weight gain intrauterine growth retardation, preterm labour increased with low socio-economic status and low education. As our observations show that $38.4 \%$ perinatal mortality is with uneducated mothers and $20.1 \%$ with partially educated mothers.

PIH (Pregnancy induced hypertension) is one of the commonest complications of pregnancy i.e. (16.6\%), and accounting for perinatal mortality of $36.2 \%$. It is inferred from this study that anemia with poor nutritional status also had distinct deleterious effect on reproductive performance as it causes IUGR, preterm deliveries or intrauterine deaths and accounted for $25 \%$ of the perinatal mortality in our study. In cases of APH which mainly includes abruptio placenta, perinatal deaths were maximum (71.4\%). Incidence of medical disease (10.3\%) in pregnancy has a reasonably good perinatal outcome as these diseases are diagnosed and treated early in pregnancy. Mothers with multiple gestation have greater perinatal morbidity and mortality of $40-0 \%$, as it carries a very high risk to the fetus mainly due to two factors (1) low birth weight with prematurity, (2) abnormal presentation. As it is well known that malpresentation by itself is associated with increased perinatal morbidity and mortality of $24 \%$, due to birth trauma, asphyxia, and operative intervention. Abnormality in FHR as determined clinically and by electronic fetal monitor 
during labour depicts intrauterine fetal hypoxia which is one of the major contributing factors for poor perinatal outcome. In our study abnormal FHR accounted for $48.4 \%$ perinatal deaths. Induction of labour itself does not have a direct effect on perinatal mortality except due to iatrogenic preterm delivery in some cases, but indirectly it may affect outcome due to the complication of pregnancy for which it was done. Perinatal mortality was $(21.7 \%)$ in our observation. PROM (premature rupture of membrane) is one of the important factors in determining perinatal mortality $(36.3 \%)$ as it is associated with increased incidence of perinatal infections and deaths. Presence of meconium was seen in $9.6 \%$ cases in our study group with a resultant mortality of $40 \%$ mainly due to infections. Highest rate of perinatal deaths $(55.5 \%)$ was seen in fetuses weighing $<1.5 \mathrm{~kg}$. and considerably high $(32.4 \%)$ when the weights were between 1.5 to 2.5 $\mathrm{kg}$. Higher incidence $(28.9 \%)$ of low birth weight babies was seen in the mothers who had one or the other risk factors. Similar trends were observed with gestational age less than 34 weeks (50\% of perinatal mortality).

Neonatal complication such as HIE is an indicator of perinatal hypoxia with or without birth trauma. Perinatal mortality with this factor was $60 \%$, in our observation. APGAR score a determinant of intrapartum hypoxia shows perinatal mortality of $78 \%$ with the APGAR score of less than 3 and $57 \%$ mortality when the APGAR score was 4-7. Such complications could be prevented if detected in time and babies delivered in optimum conditions before they worsened to irreversible stage. APGAR score is good determinant of hypoxic stage of the fetus and in spite of good resuscitative measures undertaken in a newborn with low APGAR, perinatal outcome hardly improved. Once the complications like respiratory distress sets in the neonatal period it is very difficult to save these neonates as shown by high perinatal deaths $(59 \%)$ in our study.

Hypothermia is an important determinant of neonatal outcome as neonates with low temperature $\left(<35.5^{\circ} \mathrm{C}\right)$ had significant mortality of $68 \%$. Major congenital anomalies which are incompatible with life although constitute only $1.4 \%$ was associated with $100 \%$ mortality.

Table 1: Perinatal outcome in relation to maternal age and parity.

\begin{tabular}{|lllll|}
\hline $\begin{array}{l}\text { Risk } \\
\text { factors }\end{array}$ & \multicolumn{2}{l}{$\begin{array}{l}\text { No. of } \\
\text { patients }\end{array}$} & \multicolumn{2}{l|}{$\begin{array}{l}\text { Perinatal } \\
\text { deaths }\end{array}$} \\
\hline \multicolumn{5}{l}{$\begin{array}{l}\text { No. } \% \\
\text { Maternal age }\end{array}$ (years) } \\
\hline$<18$ or $>35$ & 11 & 2.6 & 2 & 18.2 \\
\hline $19-34$ & 404 & 97.4 & 0 & 0 \\
\hline Parity & & & & \\
\hline 1 \& 2 & 340 & 81.9 & 0 & 0 \\
\hline 3 & 59 & 14.2 & 0 & 0 \\
\hline 4 \& above & 16 & 3.9 & 25 & 33.3 \\
\hline
\end{tabular}

Table 2: Perinatal outcome in relation to maternal weight and height.

\begin{tabular}{|lllll|}
\hline $\begin{array}{l}\text { Risk } \\
\text { factors }\end{array}$ & \multicolumn{2}{c}{$\begin{array}{l}\text { No. of } \\
\text { patients }\end{array}$} & \multicolumn{2}{l}{$\begin{array}{l}\text { Perinatal } \\
\text { deaths }\end{array}$} \\
& No. & $\%$ & No. & $\%$ \\
\hline Weight in & kg & & & \\
\hline$>40$ & 404 & 97.4 & 0 & 0 \\
\hline $35-40$ & 11 & 2.6 & 2 & 18.2 \\
\hline$<35$ & 0 & 0 & 0 & 0 \\
\hline Height in cm & & & \\
\hline$>145$ & 389 & 93.7 & 0 & 0 \\
\hline$<145$ & 26 & 6.3 & 4 & 15.3 \\
\hline
\end{tabular}

Table 3: Perinatal outcome in relation to socioeconomic factors.

\begin{tabular}{|lllll|}
\hline Risk factors & $\begin{array}{l}\text { No. of } \\
\text { patients }\end{array}$ & $\begin{array}{l}\text { Perinatal } \\
\text { Neaths }\end{array}$ \\
\cline { 2 - 5 } & No. $\%$ & No. & $\%$ \\
\hline $\begin{array}{l}\text { Socioeconomic status } \\
\text { (According to Pareekh scale) }\end{array}$ \\
\hline Upper class & 316 & 76.2 & 0 & 0 \\
\hline Middle class & 93 & 22.4 & 25 & 26.8 \\
\hline Lower class & 6 & 1.4 & 2 & 33.0 \\
\hline Education & & & & \\
\hline Illiterate & 78 & 18.8 & 30 & 38.4 \\
\hline Primary & 53 & 12.8 & 13 & 24.5 \\
\hline Secondary & 139 & 33.5 & 28 & 20.1 \\
\hline Graduate & 145 & 34.9 & 0 & 0 \\
\hline
\end{tabular}

Table 4: Perinatal outcome in relation to Antepartum risk factors.

\begin{tabular}{|c|c|c|c|c|}
\hline \multirow{2}{*}{$\begin{array}{l}\text { Risk } \\
\text { factors }\end{array}$} & \multicolumn{2}{|c|}{$\begin{array}{l}\text { No. of } \\
\text { patients }\end{array}$} & \multicolumn{2}{|c|}{$\begin{array}{l}\text { Perinatal } \\
\text { deaths }\end{array}$} \\
\hline & No. & $\%$ & No. & $\%$ \\
\hline \multicolumn{5}{|c|}{ H/o PIH } \\
\hline No & 346 & 83.4 & 0 & 0 \\
\hline Yes & 69 & 16.6 & 25 & 36.2 \\
\hline \multicolumn{5}{|c|}{ H/o Antepartum hemorrhage } \\
\hline No & 401 & 96.6 & 0 & 0 \\
\hline Yes & 14 & 3.4 & 10 & 71.4 \\
\hline \multicolumn{5}{|c|}{ H/o anemia } \\
\hline No & 375 & 90.4 & 0 & 0 \\
\hline Yes & 40 & 9.6 & 10 & 25 \\
\hline \multicolumn{5}{|c|}{$\begin{array}{l}\text { H/o medical disorder } \\
\text { (DM/TB/heart Ds/endocrine disorder) }\end{array}$} \\
\hline No & 372 & 89.6 & 0 & 0 \\
\hline Yes & 43 & 10.4 & 6 & 14 \\
\hline
\end{tabular}

In total there were 415 deliveries with 97 perinatal deaths, in $31 \%$ mothers there was no significant risk factors and comprised of no risk group with zero PMR. In low risk category which comprised of $46 \%$ of the sample had PMR of 198.8 . 
High risk category which was comprised of (23.1\%) had highest PMR of 614. The difference in three categories was statistically significant.

Our study concludes that a relatively small percentage of high risk gravidas are responsible for approximately $60 \%$ of all abnormal outcomes.

Perinatal mortality rate of our study can be poorly compared with National PNMR or other studies, as our study conducted in referral center where the proportion of patients with known high risk factor was very high.

Table 5: Perinatal outcome in relation to intrapartum risk factors.

\begin{tabular}{|c|c|c|c|c|}
\hline \multirow{2}{*}{$\begin{array}{l}\text { Risk } \\
\text { factors }\end{array}$} & \multicolumn{2}{|c|}{$\begin{array}{l}\text { No. of } \\
\text { patients }\end{array}$} & \multicolumn{2}{|c|}{$\begin{array}{l}\text { Perinatal } \\
\text { deaths }\end{array}$} \\
\hline & No. & $\%$ & No. & $\%$ \\
\hline \multicolumn{5}{|c|}{ H/o PROM > 24 hours } \\
\hline No & 404 & 97.3 & 0 & 0 \\
\hline Yes & 11 & 2.7 & 4 & 36.3 \\
\hline \multicolumn{5}{|c|}{ Vertex presentation } \\
\hline No & 382 & 92.0 & 0 & 0 \\
\hline Yes & 33 & 8.0 & 8 & 24.0 \\
\hline \multicolumn{5}{|c|}{ H/o induced labour } \\
\hline No & 369 & 89.0 & 0 & 0 \\
\hline Yes & 46 & 11.0 & 10 & 21.7 \\
\hline \multicolumn{5}{|c|}{ Multiple gestation } \\
\hline No & 400 & 96.4 & 0 & 0 \\
\hline Yes & 15 & 3.6 & 6 & 40 \\
\hline \multicolumn{5}{|c|}{ H/o Meconium in utero } \\
\hline No & 375 & 90.4 & 0 & 0 \\
\hline Yes & 40 & 9.6 & 16 & 40 \\
\hline \multicolumn{5}{|c|}{ H/o abnormal FHR } \\
\hline No & 384 & 92.5 & 0 & 0 \\
\hline Yes & 31 & 7.5 & 15 & 48.4 \\
\hline
\end{tabular}

Table 6: Perinatal outcome in relation to neonatal birth weight and gestational age.

\begin{tabular}{|c|c|c|c|c|}
\hline \multirow{2}{*}{$\begin{array}{l}\text { Risk } \\
\text { factors }\end{array}$} & \multicolumn{2}{|c|}{$\begin{array}{l}\text { No. of } \\
\text { patients }\end{array}$} & \multicolumn{2}{|c|}{$\begin{array}{l}\text { Perinatal } \\
\text { deaths }\end{array}$} \\
\hline & No. & $\%$ & No. & $\%$ \\
\hline \multicolumn{5}{|c|}{ Birth weight (gm) } \\
\hline$>2500$ & 295 & 71.1 & 0 & 0 \\
\hline $1500-2500$ & 111 & 26.8 & 36 & 32.4 \\
\hline$<1500$ & 9 & 2.1 & 5 & 55.5 \\
\hline \multicolumn{5}{|c|}{ Gestational age (weeks) } \\
\hline$>37$ & 317 & 76.4 & 0 & 0 \\
\hline $34-37$ & 86 & 20.7 & 33 & 38.3 \\
\hline$<34$ & 12 & 2.9 & 6 & 50.0 \\
\hline
\end{tabular}

Table 7: Perinatal outcome in relation to high risk neonatal factors.

\begin{tabular}{|c|c|c|c|c|}
\hline \multirow{2}{*}{$\begin{array}{l}\text { Risk } \\
\text { factors }\end{array}$} & \multicolumn{2}{|c|}{$\begin{array}{l}\text { No. of } \\
\text { patients }\end{array}$} & \multicolumn{2}{|c|}{$\begin{array}{l}\text { Perinatal } \\
\text { deaths }\end{array}$} \\
\hline & No. & $\%$ & No. & $\%$ \\
\hline \multicolumn{5}{|c|}{ APGAR score } \\
\hline$>7$ & 353 & 85.1 & - & - \\
\hline $4-7$ & 44 & 10.6 & 25 & 57.0 \\
\hline$<3$ & 18 & 4.3 & 14 & 78.0 \\
\hline \multicolumn{5}{|c|}{ Presence of HIE } \\
\hline No & 395 & 95.5 & - & - \\
\hline Yes & 20 & 4.8 & 12 & 60.0 \\
\hline \multicolumn{5}{|c|}{ H/o respiratory distress } \\
\hline No & 388 & 93.5 & - & - \\
\hline Yes & 27 & 6.5 & 16 & 59.0 \\
\hline \multicolumn{5}{|c|}{ H/o hypothermia } \\
\hline No & 390 & 94.0 & - & - \\
\hline Yes & 25 & 6.0 & 17 & 68.0 \\
\hline \multicolumn{5}{|c|}{ Congenital malformation } \\
\hline Nil & 407 & 98.1 & - & - \\
\hline Minor & 2 & 0.5 & 1 & 50.0 \\
\hline Major & 6 & 1.4 & 6 & 100 \\
\hline
\end{tabular}

Table 8: Perinatal outcome in comparison to maternal high risk score and neonatal high risk score.

\begin{tabular}{|c|c|c|c|c|c|c|}
\hline \multirow{2}{*}{$\begin{array}{l}\text { Maternal risk } \\
\text { category }\end{array}$} & \multicolumn{4}{|c|}{ Fetal risk category } & \multirow{2}{*}{\multicolumn{2}{|c|}{ Perinatal deaths }} \\
\hline & $0-4$ & & $5 \& 1$ & ore & & \\
\hline $\begin{array}{l}\text { No Risk } \\
(\mathrm{n}=128) \\
0-3 \text { Score }\end{array}$ & 117 & & 11 & & - & - \\
\hline $\begin{array}{l}\text { Low Risk } \\
(n=191) \\
4 \text { - } 9 \text { Score }\end{array}$ & $114 *$ & 59.7 & $77 * *$ & 40.3 & $\begin{array}{l}* *=11 \\
* *=27\end{array}$ & $\begin{array}{l}9.6 \\
35\end{array}$ \\
\hline $\begin{array}{l}\text { High Risk } \\
(\mathrm{n}=96) \\
10 \text { \& More } \\
\text { Score }\end{array}$ & $27 *$ & 28.1 & $69 * *$ & 71.9 & $*=16$ & 59.3 \\
\hline
\end{tabular}


Table 9: Distribution of risk score and pregnancy outcome.

\begin{tabular}{|c|c|c|c|c|}
\hline \multirow{2}{*}{$\begin{array}{l}\text { Maternal } \\
\text { risk category }\end{array}$} & \multicolumn{2}{|c|}{$\begin{array}{l}\text { No. of } \\
\text { patients }\end{array}$} & \multirow{2}{*}{$\begin{array}{l}\text { Perinatal } \\
\text { deaths }\end{array}$} & \multirow{2}{*}{$\begin{array}{l}\text { Perinatal } \\
\text { mortality rate } \\
\text { (PMR)/1000 } \\
\text { live births }\end{array}$} \\
\hline & No. & $\%$ & & \\
\hline No risk & 128 & 31 & 0 & 0 \\
\hline Low risk & 191 & 46 & 38 & 198.8 \\
\hline High risk & 96 & 59 & 59 & 614.5 \\
\hline
\end{tabular}

\section{DISCUSSION}

In the present study majority of the mothers were in the age group of 19-34 years (97.4\%). As in other study, Mukhopadhyay ${ }^{8}$ et al. also revealed that the teenage mothers had a higher proportion of preterm deliveries compared to in the adult mothers and had low-birthweight baby. Stillbirth rate was also significantly higher in teenage deliveries.

The most prevalent factors were low or no education of mother and low income. As our observations show that $38.4 \%$ perinatal mortality is with uneducated mothers and $20.1 \%$ with partially educated mothers. Similarly Cho C. $\mathrm{H}^{6}{ }^{6}$ used revised Edward scoring system suitable for Korean situation and used 4 criteria, demographic, obstetric, medical and miscellaneous factors. He studied 1330 pregnant women over 2 years and reported that factors like maternal age, parity, education had significant relation statistically to identify HRP.

Bharti ${ }^{9}$ et al. has also revealed that the prevalence of high risk pregnancy was found to be $31.4 \%$. Prevalence of high risk pregnancy was found significantly more in lower education group as compared to higher education group. In the lower socio-economic group, prevalence of high risk pregnancy was found significantly higher than the upper socio-economic group. Also high parity, PIH, medical disorder like anemia and PIH were prevalent factors on antepartum scale for high risk pregnancy which was similar to study done by Yucesoy et al. ${ }^{15}$

In our study most common prevalent factors were illiteracy, low income and parity of 4+, PIH (16.6\%), and anemia accounted only $8.4 \%$ with similar outcome in terms of low gestational age preterm delivery and low birth weight babies.

Our study confirmed that when mothers with no risk and with 3 or more risk factors were compared, it was observed that the presence of high risk factors in mothers, the incidence of risk in newborns also increased in most instances.

Hobel et al. ${ }^{1}$ produced a similar system based on a prospective analysis of antenatal and intrapartum factors, separately with neonatal factors and divided pregnancy into low/low risk group, low/high risk group, high/low, high/high risk groups and concluded that $46 \%$ of patients were low risk during both the prenatal and intrapartum period and incidence of high risk neonates were $6.5 \%$ and PNMR was 3/1000 live births. He observed that there was positive association between incidence of high risk neonates with the increasing score in antepartum and intrapartum period. The number of risk factors involved in his study was so high (126) that it is practically impossible and cumbersome to use it in a busy teaching hospital.

Datta $\mathrm{S}$ et al. ${ }^{3}$ used the Morrison and Olsen ${ }^{4}$ system and modified it to suit the local need to identify mothers at risk for effective management. Nosseir S. A. et al. ${ }^{5}$ used Morrison and Olsen ${ }^{4}$ system on a sample of 900 pregnant women and found that 23 high risk factors were present in $27.7 \%$ of the sample and the most frequently encountered factors were anemia (37.33\%), age 35+ $(15.6 \%)$, parity $5+(16.6 \%)$, bad obstetrics history and previous gynecological surgeries. They were directly and significantly responsible for high perinatal mortality.

The maximum perinatal mortality was observed in APH (71.4\%) due to two reasons: (1) Hypoxia due to low blood volume (2) aspiration of blood and amniotic fluid by the fetus in-utero. These results were similar with Singhal ${ }^{9}$ et al and Adekanle ${ }^{10}$ et al. which showed very high maternal and perinatal morbidity and mortality in APH and Perinatal mortality was significantly higher among the cases compared to the control group. Abnormal FHR was in second line to give maximum mortality as deceleration in FHR was the depiction of compromised, hypoxic fetus in utero. Low birth weight babies and prematurity were equally responsible for high PNMR, due to their multiple fetal complications like hypothermia, respiratory distress syndrome, hypoglycemia and electrolyte imbalance. $100 \%$ mortality was seen with major congenital malformations like anencephaly, fetal hydrops, gross hydrocephalus, major genitourinary anomalies etc.

Low risk group mothers had 50\% lower incidence of high risk neonates $(41.3 \%)$ as compared to high risk group mothers who had $84.4 \%$ of high risk neonates. Perinatal mortality rate was $198.8 \& 614.5$ in low and high risk groups respectively showing increased perinatal mortality with increased maternal high risk score.

In our study mothers with $<18$ and $>35$ years, parity $4+$, low education had significant correlation with high perinatal mortality. similar to this study operative intervention, abnormal presentation, LBW babies, multiple gestation, low gestational age and direct pregnancy related complications like $\mathrm{PIH}$, anemia were significantly related to poor reproductive outcome.

Mridula et al. ${ }^{7}$ similarly found that there was an increased risk of neonatal morbidity when maternal weight was below $45 \mathrm{~kg}$, high pregnancy order, high maternal age at delivery and previous history of stillbirth $(\mathrm{P}<0.001)$. The relation of low maternal age at delivery and history of one previous preterm birth with neonatal morbidity was 
highly significant $(\mathrm{P}<0.0001)$ which correlate with Mukhopadhayay ${ }^{8}$ study, while relation of presence of pallor and first pregnancy order with neonatal morbidity was just significant $(\mathrm{P}<0.05)$ which is similar to Zhang $\mathrm{Q}^{12}$ and Kousar ${ }^{13}$ et al. Same observations were made in our study that the mothers with height $<145$ centimeters and weight $<40 \mathrm{~kg}$ are associated with higher mortality rates i.e. $15.3 \%$ and $18.2 \%$ respectively.

APGAR score shows perinatal mortality of $78 \%$ with the APGAR score of less than 3 and $57 \%$ mortality when the APGAR score was 4-7. APGAR score is a good determinant of hypoxic stage of fetus and inspite of good resuscitative measures undertaken in a new born with low APGAR, perinatal outcome hardly improved.

Once the complications like respiratory distress sets in the neonatal period it is very difficult to save these neonates as shown by high perinatal deaths $(59 \%)$ in our study.

This study is similar to study done by Jehan ${ }^{11}$ et al. which revealed that the most common primary obstetric causes of neonatal death were preterm delivery, intrapartum asphyxia and antepartum hemorrhage.

Hypothermia is an important determinant of neonatal outcome with low temperature $\left(<35.5^{\circ} \mathrm{C}\right)$ had significant mortality of $68 \%$. Major congenital anomalies which were incompatible with life constitutes only $1.4 \%$ but associated with $100 \%$ mortality.

High risk mothers usually carry high risk babies and our study proved that with increasing maternal high risk score there was a proportionate increase in the high risk score of the fetus resulting into more NICU admissions.

\section{Limitations}

The primary limitation of the study was that, since it was conducted in a tertiary-care hospital set-up, chances of high-risk cases may be more, and it may not truly reflect the prevailing situation in a community setting.

\section{CONCLUSION}

The scoring system was found to have high sensitivity for predicting low birth weight, preterm births and perinatal mortality in high risk group but low sensitivity in low risk groups. The results obtained were comparable with studies done elsewhere.

The risk scoring system can thus be used not only as a test for predicting perinatal mortality but also as a simple and cost effective screening tool for identifying pregnancies at higher risk of perinatal mortality and morbidity so that these are subjected to the special 'high risk' care they need. Women with risk score 0-2 are considered safe and no active interference apart from simple assistance is necessary.
Funding: No funding sources

Conflict of interest: None declared

Ethical approval: The study was approved by the hospital ethics committee

\section{REFERENCES}

1. Hobel CJ, Hyvarinen MA et al. Prenatal and intrapartum high-risk screening. Am J Obstet Gynecol. 1973;117:1-9.

2. Bai NS, Mathews E, Nair PM, Sabarinathan K, Harikumar C. Perinatal mortality rate in South Indian population. J Indian Med Assoc. 1991;89:97-8.

3. Datta S, Datta KS. Identification of high risk mothers by scoring system and its correlation with perinatal outcome. J Obstet Gynecol India. 1990;40:176.

4. Morrison I, Carter L, McNamara S et al. A simplified intrapartum numerical scoring system: the prediction of high risk in labour. Am J Obstet Gynecol. 1980;138:175-80.

5. Noisser SA, Martade MM, Nofal LM et al. Screening of high risk pregnancy among mothers attending $\mathrm{MCH}$ center in Alexandria. Obstet Gynecol 1979;53:3362.

6. Cho $\mathrm{CH}$. The identification of high risk pregnancy, using a simplified antepartum risk scoring system. Taehan-Kanho. 1991;30(3):49-65.

7. Mrudula K. Lala, N. J. Talsania. Study of evaluation an prediction of neonatal mortality and morbidity using ICMR antenatal scoring method. Indian $\mathbf{J}$ Comm Med. 2001;26(4):10-2.

8. Mukhopadhyay P, Chaudhuri RN, Paul B. Hospitalbased perinatal outcomes and complications in teenage pregnancy in India. J Health Popul Nutr. 2010 Oct;28(5):494-500.

9. Singhal S, Nymphaea, Nanda S. Maternal and perinatal outcome in antepartum hemorrhage: a study at a tertiary care referral institute. Intern $\mathbf{J}$ Gynecol Obstet. 2007;9(2):1-6.

10. Adekanle DA, Adeyemi AS, Fadero FF. Antepartum hemorrhage and pregnancy outcome in LAUTECH teaching hospital, southwestern Nigeria. J Med Med Sci. 2011 Dec;2(12):1243-7.

11. Jehan I, HarrisH, Salat S, Zeb A, Mobeen N, Pasha O, McClure EM, Moore J, Wright LL, Goldenberg RL. Neonatal mortality, risk factors and causes: a prospective population-based cohort study in urban Pakistan. Bull WHO. 2009;87:130-8.

12. Zhang Q, Ananth CV, Rhoads GG, Li Z. The impact of maternal anemia on perinatal mortality: a population-based, prospective cohort study in China Ann Epidemiol. 2009;19(11):793-9.

13. Kousar T, Memon Y, Sheikh S, Memon S, Sehto R. Risk factors and causes of death in neonates. Rawal Med J. 2010;35(2):205-8.

14. Casey MB, McIntire DD, Leveno KJ. The continuing value of the APGAR score for the assessment of newborn infants. N Engl J Med. 2001;344(7):467-71.

15. Yücesoy G, Ozkan S, Bodur H, Tan T, Calişkan E, Vural B, Corakçi A. Maternal and perinatal outcome 
in pregnancies complicated with hypertensive disorder of pregnancy: a seven year experience of a tertiary care center. Arch Gynecol Obstet. 2005;273(1):43-9.

16. Zupan J, Aahman E. Neonatal and perinatal mortality: country, regional and global estimates,
2004. In: Zupan J, Aahman E, eds. WHO Data. Geneva: World Health Organization; 2007: 1-14.

DOI: $10.5455 / 2320-1770 . i j r \operatorname{cog} 20140910$

Cite this article as: Jain S, Anand S, Aherwar R.

High risk scoring for prediction of pregnancy

outcome: a prospective study. Int J Reprod

Contracept Obstet Gynecol 2014;3:516-22. 